\title{
Correction to: Ultra-thin nanosheet-assembled accordion-like Ni-MOF for hydrazine hydrate amperometric sensing
}

\author{
Shuai Cao ${ }^{1} \cdot$ Shasha Zheng ${ }^{1} \cdot$ Huan Pang ${ }^{1}$ \\ Published online: 4 July 2020 \\ (C) Springer-Verlag GmbH Austria, part of Springer Nature 2020
}

Correction to: Microchimica Acta (2020) 187:168

https://doi.org/10.1007/s00604-020-4153-7

The published article is revised due to diagram errors. The authors express their sincere apology, and corrected Figure 2a (XPS), Figure S4 (IR), and Figure S7 (XPS) are given.

The online version of the original article can be found at https://doi.org/ $10.1007 / \mathrm{s} 00604-020-4153-7$

\section{Huan Pang}

panghuan@yzu.edu.cn

1 School of Chemistry and Chemical Engineering, Institute for Innovative Materials and Energy, Yangzhou University, Yangzhou, Yangzhou 225002, Jiangsu, People's Republic of China 
a

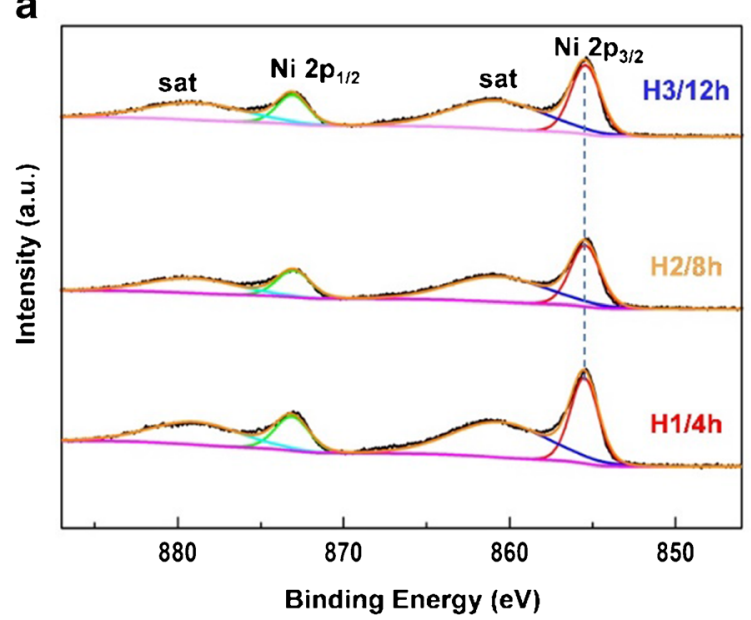

b

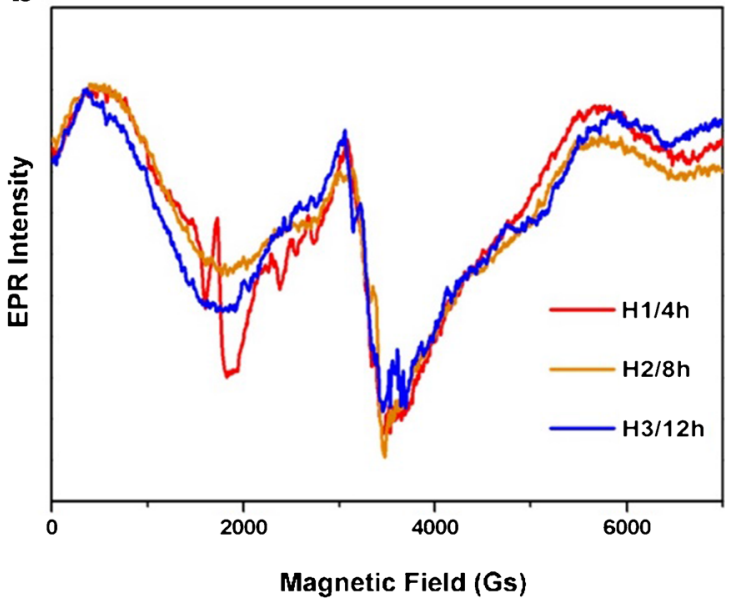

Fig. 2. a) XPS patterns; b) EPR spectra of the ultra-thin nanosheet Ni-MOF 25

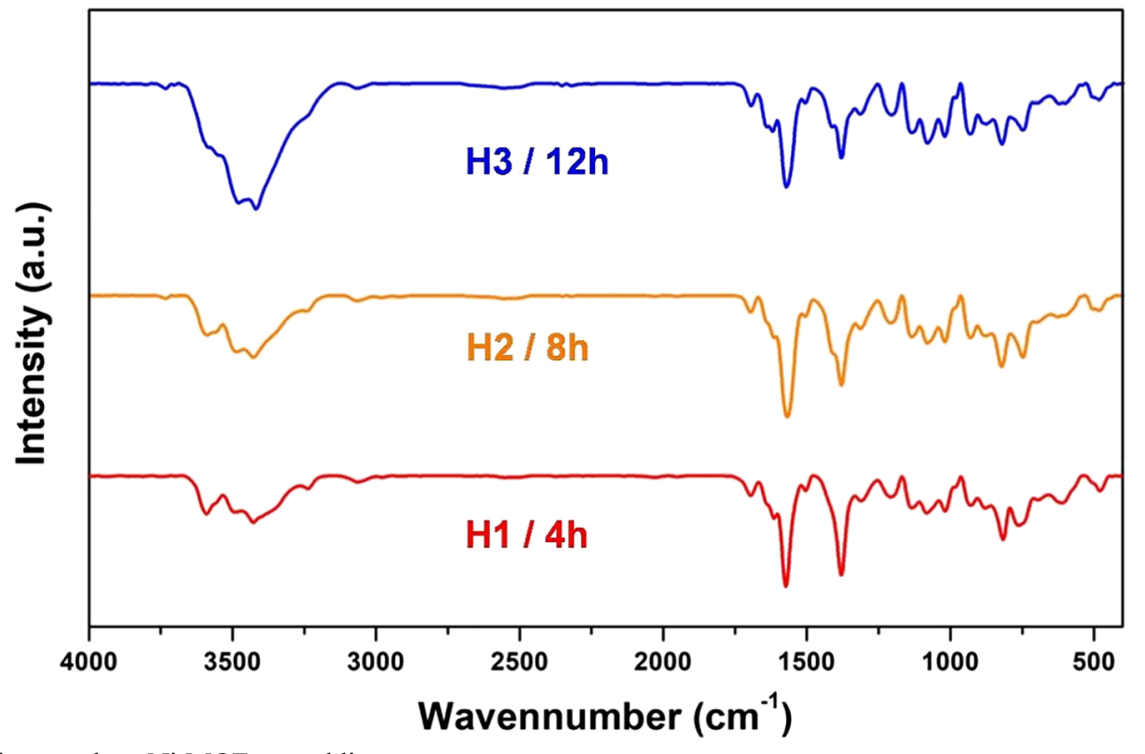

Fig. S4. FTIR of ultra-thin nanosheet Ni-MOF assemblies 

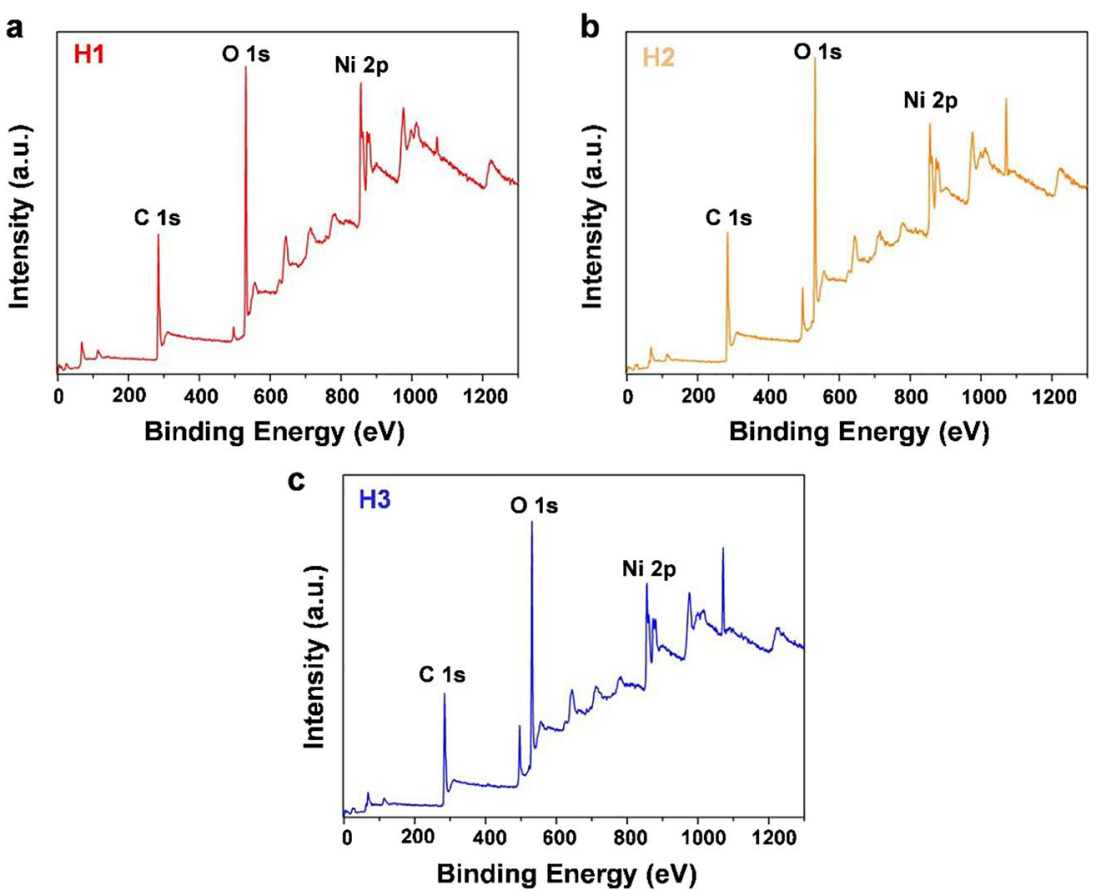

Fig. S7. XPS patterns of the ultra-thin nanosheet Ni-MOF assemblies. a) the survey of H1. b) the survey of H2. c) the survey of H3

\section{Compliance with ethical standards}

Conflict of interest The authors declare that they have no competing of interests.
Publisher's note Springer Nature remains neutral with regard to jurisdictional claims in published maps and institutional affiliations. 